\title{
EEG correlates of mescaline-induced pathological aggression in rats
}

\author{
RONALD N. SHULL and ROBERT J. SBORDONE \\ Department of Psychiatry \\ University of California, School of Medicine, Los Angeles, California 90024 \\ and \\ DAVID A. GORELICK \\ Departments of Psychiatry and Pharmacology \\ University of California, School of Medicine, Los Angeles, California 90024
}

\begin{abstract}
Electroencephalographic changes in limbic and cortical structures in freely moving male rats were examined before and after the delivery of footshock, the presentation of a sedated opponent, and the administration of mescaline hydrochloride $(50 \mathrm{mg} / \mathrm{kg}$ ip). These stimuli presented separately did not produce significantly abnormal EEG activity. However, all three presented together produced epileptiform spike and wave activity in the basolateral amygdala of all the subjects. This activity was associated with biting of the sedated opponent, who generally remained passive and never attempted aggressive retaliation. Epileptiform activity was never seen in the ventral hippocampus or cerebral cortex. These results suggest an association between mescaline-induced pathological aggression and abnormal electrical activity in the amygdala. A possible mechanism for this association is discussed.
\end{abstract}

A common experimental paradigm for studying irritable aggression consists of exposing a pair of animals to electric footshock. Because this paradigm calls for using animals not previously exposed to electric shock, the effects of previous learning or conditioning have been assumed to be unimportant (Ulrich \& Azrin, 1962). Under these conditions, rats typically assume an upright "boxing" posture and strike each other with their forepaws when footshock is delivered. Unlike some other aggression paradigms, biting or other injurious behavior rarely occurs, and the fighting seldom outlasts the termination of footshock (Sbordone \& Carder, 1974). The aggressive behavior of rats placed in this situation has been shown to be reliably observed, readily quantified, and easily replicated (Sbordone, 1976).

Using this footshock-elicited aggression paradigm, Sbordone and his co-workers have reported that mes-

This research was supported in part by NIH Grant RR-05756 to R. J. Sbordone. D. A. Gorelick was supported by a Bank of America-Giannini Foundation Fellowship in Medical Research. We gratefully acknowledge the advice and assistance of Frank $\mathbf{R}$. Ervin and Henry $M$. Lesse in the preparation of this manuscript. R. J. Sbordone's present address is Department of Physical Medicine and Rehabilitation, U.C. Irvine Medical Center, 101 City Drive South, Orange, California 92668. D. A. Gorelick's present address is Brentwood VA Medical Center, Los Angeles, California 90073. Address reprint requests to Ronald N. Shull, 10742 Woodbine Street, Los Angeles, California 90034. caline not only increases the duration of fighting, but also produces, in rats, "pathological" aggression which consists of a change in the actual topography of the fighting episodes from upright boxing to nearlethal biting (Sbordone, Wingard, Elliott, \& Jervey, 1978). Furthermore, the fighting episodes become less tied to the delivery of shock (Sbordone, 1976). Mescaline-treated rats, unlike their untreated counterparts, will attack dead or immobile rats in a footshock situation, but will not attack inanimate objects or a cloth replica of a rat (Carder \& Sbordone, 1975). The marked change and increase in aggressive behavior due to mescaline has been shown to occur reliably upon repeated testing with the drug and is relatively unaffected by previous fighting experience or by the size of the testing enclosure (Sbordone, 1976). Recently, the administration of mescaline has been shown to reliably produce this pathological aggression in rats regardless of their age or strain (Sbordone et al., 1978) or any moderate changes in drug dosage (Sbordone, Wingard, Gorelick, \& Elliott, 1979).

The limbic system plays a major role in the regulation of aggressive behavior in rats (Moyer, 1976). For example, Frederickson and his co-workers have shown that changes in hippocampal EEG activity are related to the topography of the species-typical aggressive behavior of the rat (Frederickson, Miczek, Zurawin, \& Frederickson, 1977). Similarly, Pinel and his co-workers observed increases in species- 
typical aggressive behavior in rats with experimentally induced epileptic foci in temporal lobe structures (Pinel, Treit, \& Rovner, 1977). Mescaline does alter electrical activity in limbic and other brain areas. In rats and rabbits, mescaline $(5-400 \mathrm{mg} / \mathrm{kg}$ iv) causes dose-dependent EEG desynchronization (increased low voltage, fast activity) in cortical and subcortical areas (Speck, 1958; Takeo \& Himwich, 1967; Wolforth, 1971). Three- to 5-Hz paroxysmal activity in limbic areas has also been noted after mescaline (Takeo \& Himwich, 1967).

With the above in mind, it seems possible that mescaline produces, in the electrical activity of the limbic system in rats, changes that are correlated with the onset of this pathological aggression. The purpose of the present study is to investigate the electroencephalographic changes in selected limbic and cortical brain areas associated with mescalineinduced pathological aggression in rats exposed to a footshock-elicited aggression paradigm.

\section{METHOD}

\section{Subjects}

The subjects were 20 experimentally naive male Sprague-Dawley rats (Simonsen Breeding Laboratory, Gilroy, California) more than 100 days old $(400-500 \mathrm{~g})$. Subjects were housed individually under a 14:10-h light-dark cycle, with food and water continuously available. All experiments were done during the middle of the light cycle.

\begin{abstract}
Apparatus
Aggression testing was performed in apparatus previously described (Sbordone et al., 1978). Briefly, this consisted of a $30-\mathrm{cm}$ diam $\times 30$-cm-high Plexiglas cylindrical chamber. Electric footshock was delivered through the grid floor from a Davis Model 276 shock generator and a Model 255 grid scrambler. Behavioral data and parameters of shock delivery were recorded concurrently on digital counters, cumulative timers, and an Esterline-Angus 20-channel event recorder. EEG data was recorded on a Grass Model III-B eight-channel EEG recorder. The aggression test chamber was housed in an electrically shielded, soundproof room adjacent to the room housing the rest of the apparatus. Electrical connections between the two rooms were made by shielded cable through a wall-mounted junction box. The cable for EEG connections ran through a swivel connector suspended from the ceiling of the room, thus allowing subjects to be free moving. The test chamber could be observed from the adjacent room through a one-way glass window.
\end{abstract}

\section{Surgery}

The rats were paired on the basis of a similar body weight (within $10 \mathrm{~g}$ ), with one member of each pair being selected randomly for electrode implantation. Two concentric electrodes of local manufacture were stereotaxically implanted under pentobarbital anesthesia unilaterally in the basolateral amygdala $(-.2 \mathrm{~mm}$ A-P to bregma, $5.0 \mathrm{~mm} \mathrm{~L}$ to midline, $8.9 \mathrm{~mm} \mathrm{~V}$ from dura) and the ventral hippocampus cornu ammonis ( $-3.2 \mathrm{~mm}$ A-P to bregma, $5.3 \mathrm{~mm} \mathrm{~L}$ to midline, $8.5 \mathrm{~mm} \mathrm{~V}$ from dura), using the coordinate system of Pellegrino and Cushman (1967). Each electrode consisted of an outer terminal of stainless steel tubing (outer diameter: $.4 \mathrm{~mm}$ ) surrounding an inner terminal of insulated copper wire. The terminals were insulated to within $.5 \mathrm{~mm}$ of the tip, with the exposed tips $.8 \mathrm{~mm}$ apart. Four cortical electrodes consisting of stainless steel jeweler's screws were posi- tioned in contact with the dura through burr holes in the skull, with two over the anterior portion of the cortex (approximately $+3.0 \mathrm{~mm}$ A-P to bregma, $4.0 \mathrm{~mm} \mathrm{~L}$ to midline) and two over the posterior portion of the cortex (approximately $-6.0 \mathrm{~mm}$ A-P to bregma, $4.0 \mathrm{~L}$ to midline) in a bilateral fashion. A ground electrode was mounted on the midline of the skull approximately $3 \mathrm{~mm}$ behind lambda to avoid cortical interference. Each electrode was connected by insulated copper wire to a chronic electrode connector fixed to the skull with acrylic dental cement. Following surgery, a 2-week recovery period was allowed prior to the beginning of behavioral testing.

\section{Histology}

Electrode placement was confirmed histologically after the experiment. After being deeply anesthetized, subjects were perfused by cardiac puncture with normal saline $(50 \mathrm{ml})$, followed by $10 \%$ Formalin $(100 \mathrm{ml})$. Following decapitation, the brains were removed, set in $10 \%$ Formalin, blocked, frozen, and frontally sectioned at $80 \mu$ intervals. Every other section through the electrode sites was mounted and stained by the Nissl method. All subjects were found to have accurate electrode placement. A representative example is given in Figure 1.

\section{Procedure}

Every implanted subject received two sessions of aggression testing with the same opponent at least 1 week apart. Each test session consisted of five consecutive stages. First, the implanted subject was placed in the aggression test chamber alone and its EEG recorded for $4 \mathrm{~min}$ (Stage 1) to obtain baseline data. Then the subject was exposed to 30 footshocks $(4.0 \mathrm{~mA}, 1.5$-sec dura-

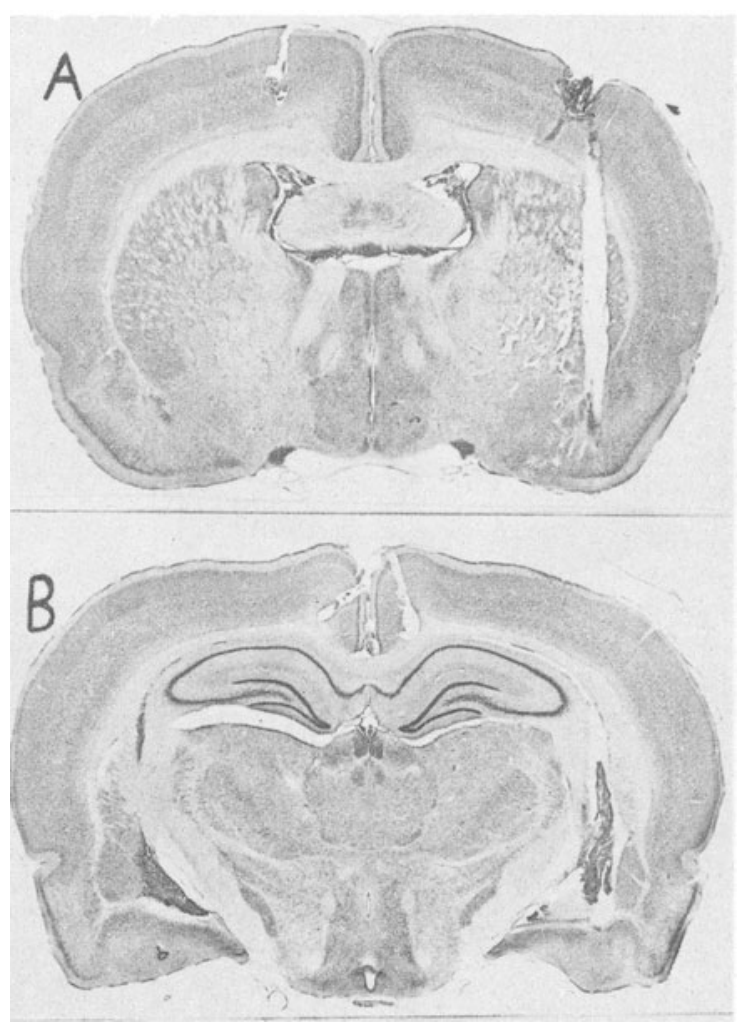

Figure 1. Photomicrographs of frontal sections showing the locus of unilateral (right) electrode placement for a representative animal. Section A shows placement in the basolateral amygdala, while Section B shows placement in the ventral hippocampus. 
tion, 30-sec intershock interval) to determine the effects of shock exposure by itself. The EEG was recorded for $4 \mathrm{~min}$ immediately after the last shock (Stage 2). The implanted subject was then given mescaline hydrochloride $(50 \mathrm{mg} / \mathrm{kg} \mathrm{ip})$, and $10 \mathrm{~min}$ later the EEG was recorded for 4 min to determine the effects of mescaline by itself (Stage 3). Stage 4 began by sedating the paired unimplanted opponent with pentobarbital $(20 \mathrm{mg} / \mathrm{kg}$ ip) and placing him in the test chamber with the implanted subject. The EEG was then recorded for 4 min to determine the effect of exposure to the opponent. The fifth stage consisted of exposing the pair to footshock $(4.0 \mathrm{~mA}, 1.5-\mathrm{sec}$ duration, 30-sec intershock interval) until biting occurred. After the shocks were stopped, the EEG was recorded for approximately $10 \mathrm{~min}$ (Stage 5) to determine the association between mescaline-induced pathological aggression and EEG activity. Throughout the session, an observer seated in the adjacent room pressed one of four microswitches to continuously classify the implanted subject's behavior into one of four categories, using the criteria of Sbordone and Garcia (1977): motionless, nonaggressive behavior, aggressive behavior without biting, or aggressive behavior with biting.

\section{Data Analysis}

The entire EEG recording for each implanted subject was visually scanned to determine the occurrence of epileptiform spike and wave activity, expressed as duration per $100 \mathrm{sec}$ of EEG recording. The criteria of Gibbs and Gibbs (1945) were used in defining epileptiform activity by comparing their pictorial examples with those cases of possible epileptiform activity seen in the present study. In addition, $1 \mathrm{sec}$ of every $20 \mathrm{sec}$ of nonepileptiform activity was manually scored by counting the number of cycles that occurred during that second of recording time (frequency) and by calculating the average height of the cycles within that same period and comparing this value with the height of an artificially produced standardized $(100 \mu \mathrm{V})$ cycle display (amplitude). Each variable was analyzed independently for each electrode site (anterior-posterior cortex, basolateral amygdala, ventral hippocampus) using a one-factor (stage of experiment) ANOVA with repeated measures. A posteriori comparisons among stages were done using Newman-Keuls multiple comparison tests.

\section{RESULTS}

Four of the original subjects that underwent surgery died either during the surgery or during the postoperative recovery period. Thus, results are based on the surviving six subjects. All implanted subjects exhibited typical mescaline-induced pathological aggression (defined as biting attacks, usually producing injury to the victim's facial area) during Stage 5, producing a mean of $7.4(\mathrm{SD}=3.6)$ biting attacks on their opponents. No biting attacks were initiated by any of these subjects during Stage 4 . All anesthetized opponents remained markedly sedated and ataxic throughout the experimental sessions, never exhibiting any aggressive behavior.

There was a significant decrease in EEG amplitude during the experiment in the cortical $[F(4,20)=6.6$, $\mathrm{p}<.005]$, amygdaloid $[\mathrm{F}(4,20)=97.2, \mathrm{p}<.00001]$, and hippocampal $[\mathrm{F}(4,20)=10.9, \mathrm{p}<.001]$ leads (Figure 2). A posteriori tests revealed that this was because of decreases during Stages 3 and 4 (all ps $<.01)$. There were no significant changes in EEG frequency observed during the experiment in any of the leads $[F(4,20)=.5, p>.50$, for the cortex; $F(4,20=$ $.7, \mathrm{p}>.50$, for the amygdala; $F(4,20)=.6, \mathrm{p}>.50$,

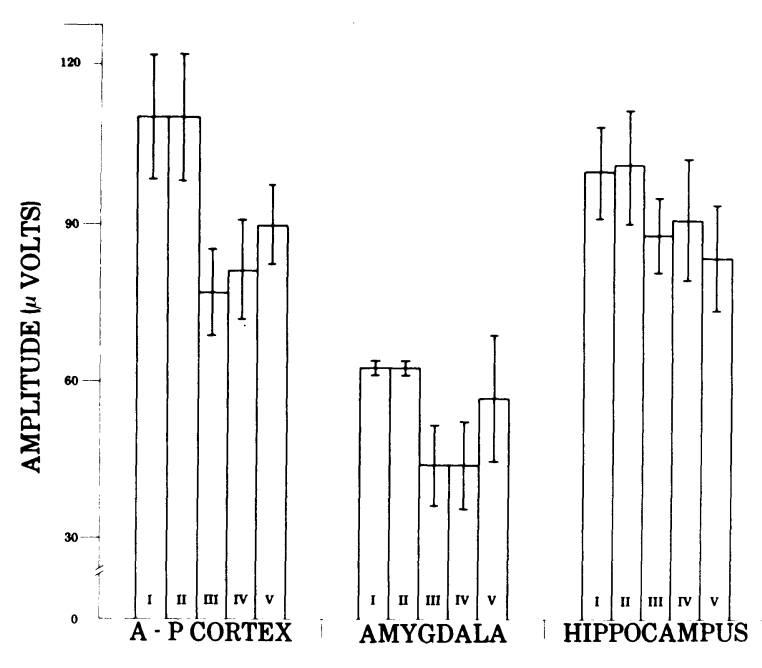

Figure 2. EEG amplitude in cortical, amygdaloid, and hippocampal leads during stages of experimental session. Each column represents the mean (SD) of six implanted rats. EEG records were analyzed as described in the method section.

for the hippocampus]. The mean predominant frequency was about $22 \mathrm{~Hz}$ for the cortical leads, $28 \mathrm{~Hz}$ for the amygdaloid lead, and $19 \mathrm{~Hz}$ for the hippocampal lead.

Epileptiform activity occurred only in the amygdala. None was ever observed in either the cortex or ventral hippocampus. This activity consisted of episodes of high voltage, $6-10-\mathrm{Hz}$ spike and wave activity lasting between .3 and $3.0 \mathrm{sec}$ and matched very closely previous examples of such activity given by Gibbs and Gibbs (1945). The frequency and amplitude of these episodes were calculated using the techniques described in the method section above, except that each episode was analyzed in its entirety, as opposed to 1 of every $20 \mathrm{sec}$ of activity. This epileptiform activity occurred significantly more often during Stage 5 than during any other stage of the experiment $[F(4,20)=13.7, p<.001]$. All six implanted subjects had epileptiform activity during Stage 5 (mean duration per $100 \mathrm{sec}$ of $3.5 \mathrm{sec}$, range between 1.3 and $7.5 \mathrm{sec}$ ). Three of these subjects also showed such activity during Stage $3(.5-1.0 \mathrm{sec} /$ $100 \mathrm{sec}$ ). Although no significant changes in ongoing behavior were observed during these episodes of epileptiform activity, each episode was followed by a series of biting attacks after a lag of no more than $10 \mathrm{sec}$. The correlation between the duration of epileptiform activity and the number of biting attacks was not statistically significant $(r=.14, p<$ $.25)$.

After the initial experimental sessions were completed, three of the implanted subjects were randomly chosen to receive a third injection of mescaline hydrochloride. After a waiting period of from 15 to $20 \mathrm{~min}$ (for each animal), each subject was 
given 30 footshocks while alone in the chamber (same shock parameters as above). At the end of this shock period, the subject's EEG was recorded for $4 \mathrm{~min}$. No epileptiform activity was observed in any of the monitored neural areas in any of these animals.

\section{DISCUSSION}

The data presented above suggest that mescalineinduced pathological aggression is correlated, at least in a temporal sense, with epileptiform activity in the amygdala. The specificity of this association is supported by the fact that this epileptiform activity was never observed in the monitored cortical or ventral hippocampal areas and occurred almost exclusively under the conditions which produced the biting attacks (Stage 5). However, the absence of a significant correlation between the duration of epileptiform activity and the number of biting attacks produced during Stage 5, as well as the failure to observe significant changes in ongoing behavior during the onset of these epileptiform episodes, suggests that there is not a strong one-to-one relationship between the epileptiform activity seen in the basolateral amygdala and the biting attacks.

The principle effect of animal aggression, at least as viewed by some (Nagel \& Kummer, 1974), is the establishment of organized cooperative social relationships within the group through competition, not the demise of other members of the group. Behavior which significantly exceeds the typical aggressive repertoire of a particular species in terms of character and intensity can truly be defined as "pathological." The species-typical repertoire of aggressive behaviors in any situation depends to some degree on the use of social signals which serve such functions as preventing attack, inducing withdrawal, or showing submission.

It has been shown by Sbordone and Elliott (1978) that a normal, undrugged rat will bite another rat anesthetized with pentobarbital when both are exposed to electric footshock. This biting occurs only if the anesthetized victim rat displays ataxic movements and submissive postures; it does not occur if the anesthetized victim rat remains immobile or regains control of its movements and runs about the test chamber. It has also been demonstrated (Sbordone \& Garcia, 1977) that a normal, undrugged rat will bite a mescaline-treated rat when both are given electric footshock and that the level of pathological aggression shown on the part of the undrugged rat can be significantly increased by giving it an injection of mescaline. The results of both of these studies suggest that the pathological aggression observed is due, in part, to a disruption of social signals between attacker and victim that would normally regulate the severity of the aggressive behavior displayed.
It can be seen from the results of the present experiment that mescaline produced in the attacking rats a significant decrease in EEG amplitude. This finding agrees with previous findings (Speck, 1958) which demonstrated that mescaline produces EEG desynchronization in rats. The absence of any accompanying increase in EEG frequency may have been due to the already high frequencies present when mescaline was administered because of the preceding handling and footshock exposure. EEG desynchronization is viewed by some as a sign of increased arousal (Moruzzi \& Magoun, 1949). It seems reasonable to assume, then, that the observed decrease in EEG amplitude is a possible sign of arousal which, when coupled with the epileptiform activity seen in the amygdala after footshock, could have augmented the severity of the attacker's aggressive behavior in the present experiment. Both the change in EEG amplitude and the appearance of epileptiform activity may have been related to a change in the activity of a specific neurotransmitter, such as norepinephrine, which has also been implicated in the production of shock-elicited aggression (Thoa, Eichelman, \& Ng, 1972). Visual observation during the experiment indicated that the mescaline-treated rat attacked his anesthetized victim much more vigorously than a normal, undrugged rat would have in the same experimental situation.

It is not necessary to assume that the abnormal neuronal activity seen during the present experiment was the sole cause of the severe biting observed. The absence of a significant correlation between the duration of epileptiform activity and the number of biting attacks observed, as well as the absence of changes in ongoing behavior during periods of epileptiform activity, suggests that such activity does not directly induce pathological aggression. Instead, such epileptiform activity may signal the release of aggressive behavior from normal species-typical controls, thus permitting other variables, such as the opponent's behavior, to trigger pathological aggression. The findings of the present study can be explained by the hypothesis that the observed abnormal neuronal activity of the attacking rat intensified the amount and degree of aggression demonstrated, but that this aggression was due initially to a disruption of social signals between the attacker and the victim.

Sbordone and Garcia (1977) showed that the severity of biting attacks between a pair of rats given footshock was significantly greater when both rats were mescaline-treated (79\% of attacks produced serious injury to the victim) than when only the victim was mescaline-treated (14\% of attacks produced serious injury to the victim). The results of the present experiment would indicate that the findings of Sbordone and Garcia (1977) are explainable in terms of an interaction between the abnormal 
neuronal activity of the attacker and the ataxic and submissive movements of the victim. Neither condition by itself is sufficient to produce the level of pathological aggression seen. The present findings are also in line with clinical evidence which demonstrates that incidents of violent behavior seen in humans suffering from temporal lobe seizures are more common during interictal periods than during periods of seizure activity (Bear \& Fedio, 1977; Falconer, 1973).

A perfect synchronization between the limbic system and neocortex is necessary for an adequate and reasonable response to environmental stimuli (Mark \& Ervin, 1970). It is possible that the abnormal amygdaloid activity observed in the present study was part of a larger neuronal disturbance. It has been shown that electrical abnormalities which appear localized in the anterior temporal region can originate in the periamygdaloid region or even in the diencephalon or mesencephalon (Ajmone-Marson \& Rolston, 1957). More work needs to be done on this phenomenon, particularly since it has been suggested that mescaline's ability to produce this type of aggression in rats exposed to footshock is not shared by other hallucinogens or nonhallucinogenic analogues (Sbordone et al., 1979).

\section{REFERENCES}

Ajmone-Marsan, C., \& Ralston, B. L. The epileptic seizure. Springfield, Ill: Thomas, 1957.

BEAR, D. M., \& Fedio, P. Quantitative analysis of interictal behavior in temporal lobe epilepsy. Archives of Neurology, 1977, 34, 454-467.

Carder, B., \& Sbordone, R. J. Mescaline-treated rats attack immobile targets. Pharmacology, Biochemistry, and Behavior, 1975, 3, 923-925.

Falconer, M. A. Reversibility by temporal lobe resection of the behavioral abnormalities of temporal lobe epilepsy. New England Journal of Medicine, 1973, 289, 451-455.

Frederickson, C. J., Miczer, K. R., Zurawin, R. A., \& Frederickson, M. H. Hippocampal EEG correlates of intraspecies aggressive behavior in the rat. Brain, Behavior, and Evolution, 1977, 14, 352-367.

Gib8s, F. A., \& GiвBs, E. L. Atlas of electroencephalography. Cambridge, Mass: Addison-Wesley, 1945.
Mark, V. H., \& Ervin, F. R. Violence and the brain. New York: Harper \& Row, 1970.

Moruzzi, G., \& Magoun, H. W. Brain stem reticular formation and activation of the EEG. EEG Clinical Neurophysiology, $1949,1,455-473$.

MOYER, K. E. The psychobiology of aggression. New York: Harper \& Row, 1976.

NAGEL, U., \& KUMMER, H. Variation in cercopithecoid aggressive behavior. In R. L. Holloway (Ed.), Primate aggression, territoriality, and xenophobia. New York: Academic Press, 1974.

Pellegrino, L. J., \& Cushman, A. J. A stereotaxic atlas of the rat brain. New York: Appleton-Century-Crofts, 1967.

Pinel, J. P., Treit, D., \& Rovner, L. I. Temporal lobe aggression in rats. Science, 1977, 197, 1088-1089.

Sbordone, R. J. A rat model of violent attack behavior. Dissertation Abstracts, 1976, 37, 213.

Sbordone, R. J., \& Carder, B. Mescaline and shock-induced aggression in rats. Pharmacology, Biochemistry, and Behavior, $1974,2,777-782$.

Sbordone, R. J., \& ElliotT, M. L. The topography of aggressive behavior of the attacker is determined by the behavior of the victim. Aggressive Behavior, 1978, 4, 345-362.

Sbordone, R. J., \& Garcia, J. Untreated rats develop "pathological" aggression when paired with a mescaline-treated opponent in a shock-elicited aggression situation. Behavioral Biology, 1977, 21, 451-461.

Sbordone, R. J., Wingard, J. A., Elliott, M. L., \& Jervey, J. Mescaline produces pathological aggression in rats regardless of age or strain. Pharmacology, Biochemistry, and Behavior, 1978, 8, 543-546.

Sbordone, R. J., Wingard, J. A., Gorelick, D. A., \& Elliott, M. L. Severe aggression in rats induced by mescaline but not other hallucinogens. Psychopharmacology, 1979, 66, 275-280.

SPECK, L. B. Electroencephalographic changes in the rat with mescaline intoxication. Journal of Pharmacology and Experimental Therapeutics, 1958, 122, 201-206.

TAkeo, Y., \& Himwich, H. E. Comparative electroencephalographic study of phenylethylamines and their methoxy derivatives. Archives Internationale de Pharmacodynamie et Therapie, 1967, 166, 47-59.

ThoA, N. B., Eichelman, B., \& NG, K. Y. Shock-induced aggression: Effects of 6-hydroxydopamine and other pharmacological agents. Brain Research, 1972, 43, 467-475.

Ulrich, R. E., \& AzRin, N. H. Reflexive fighting in response to aversive stimulation. Journal of the Experimental Analysis of Behavior, 1962, 5, 511-520.

Wolforth, S. The effect of ether derivatives of 3, 4, 5-trimethoxybenzyl alcohol on the central nervous system. Dissertationes Pharmaceuticae et Pharmacologicae, 1971, 23, 89-111.

(Received for publication September 30, 1980; revision accepted May 5, 1981.) 